\title{
Safety of perioperative cerebrospinal fluid drain as a protective strategy during descending and thoracoabdominal open aortic repair
}

\author{
Mohamed Abdelbaky, MD, ${ }^{\mathrm{a}}$ Dimitra Papanikolaou, MD, ${ }^{\mathrm{a}}$ Mohammad A. Zafar, MBBS, ${ }^{\mathrm{a}}$ \\ Hesham Ellauzi, MD, ${ }^{a}$ Maryam Shaikh, MD, ${ }^{a}$ Bulat A. Ziganshin, MD, PhD, ${ }^{a, b}$ and \\ John A. Elefteriades, MD, PhD (hon) ${ }^{\mathrm{a}}$
}

\section{ABSTRACT}

Objective: We present our experience with routine application of the cerebrospinal fluid (CSF) drain (CSFD) during open aortic repair.

Methods: We retrospectively reviewed 100 patients with descending thoracic aortic aneurysm (DTAA) or thoracoabdominal aortic aneurysm (TAAA) or who underwent CSFD insertion before open repair between 2006 and 2017. All CSFDs were inserted by the cardiovascular anesthesia team. The goal was to keep intracranial pressure $<10 \mathrm{~mm} \mathrm{Hg}$ during the surgical procedure by draining CSF at a rate of 20 to $30 \mathrm{~mL} / \mathrm{h}$. Postoperatively, CSFD was set to maintain the lumbar pressure $<10 \mathrm{~mm} \mathrm{Hg}$ to reduce the risk of postoperative paraplegia. CSFD was part of our standard cord protection regimen.

Results: The mean patient age was $65.4 \pm 11.7$ years, and $60(60 \%)$ were male. A CSFD was successfully inserted in all patients. The mean hospital length of stay was $11.9 \pm 11.8$ days, and hospital mortality was $6 \%$. Postoperative transient paresis was observed in 4 patients $(4 \%)$, and permanent paraplegia was seen in $2(2 \%)$. CSFDrelated complications were reported in 14 patients $(14 \%)$. Complications included persistent CSF leakage and blood-tinged CSF with and without intracranial hemorrhage and spinal cutaneous fistula in $7(7 \%), 9(9 \%)$, and $1(1 \%)$, respectively. Longterm survival was excellent (68.4\% at 10 years).

Conclusions: CSFD is a safe practice when applied routinely as an adjunct strategy to prevent paraplegia in surgical management of DTAA and TAAA. We feel that this contributed to good early and late clinical results. (JTCVS Techniques 2021;6:1-8)

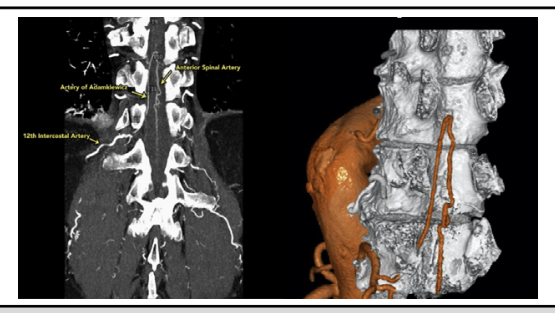

Three-dimensional reconstruction of the anterior spinal artery (T12) using the dual-intensity Yale technique.

\section{CENTRAL MESSAGE}

Cerebrospinal fluid drainage is a

safe practice when applied

routinely as an adjunct strategy to

prevent paraplegia under surgical

management of descending

thoracic aortic aneurysm and

thoracoabdominal aortic aneu-

rysm. We feel that this contrib-

uted to good early and late results.

\section{PERSPECTIVE}

There is currently a class IB recommendation for cerebrospinal fluid (CSF) drainage for patients at high-risk of spinal cord ischemia (SCI) undergoing open descending thoracic aortic aneurysm (DTAA) or thoracoabdominal aortic aneurysm (TAAA) repair, according to the American College of Cardiology Foundation/American Heart Association guidelines, and a class IB recommendation for CSF drain (CSFD) use in all patients according to the European Association for Cardiothoracic Surgery guidelines. Here we present our experience applying a CSFD routinely as a protective strategy to prevent SCI in DTAA and TAAA open repair.

See Commentaries on pages 9 and 11.
From the a Aortic Institute at Yale-New Haven Hospital, Yale University School of Medicine, New Haven, Conn; and ${ }^{\mathrm{b}}$ Department of Cardiovascular and Endovascular Surgery, Kazan State Medical University, Kazan, Russia.

Received for publication Dec 2, 2020; accepted for publication Dec 2, 2020; available ahead of print Jan 9, 2021.

Address for reprints: John A. Elefteriades, MD, PhD (hon), Aortic Institute at YaleNew Haven, Yale University School of Medicine, 789 Howard Ave, Clinic Building CB 317, New Haven, CT 06519 (E-mail: john.elefteriades@yale.edu).
2666-2507

Copyright (C) 2021 The Authors. Published by Elsevier Inc. on behalf of The American Association for Thoracic Surgery. This is an open access article under the CC BY-NC-ND license (http://creativecommons.org/licenses/by-nc-nd/4.0/). https://doi.org/10.1016/j.xjtc.2020.12.039 


\section{Abbreviations and Acronyms \\ $\mathrm{CSF}=$ cerebrospinal fluid \\ CSFD $=$ cerebrospinal fluid drain \\ $\mathrm{CT}=$ computed tomography \\ CTA = computed tomography angiography \\ DTAA $=$ descending thoracic aortic aneurysm \\ MRA $=$ magnetic resonance angiography \\ SCI = spinal cord ischemia \\ $\mathrm{TAAA}=$ thoracoabdominal aortic aneurysm}

Video clip is available online.

Spinal cord ischemia (SCI) is a rare but devastating complication following descending thoracic aortic aneurysm (DTAA) and thoracoabdominal aortic aneurysm (TAAA) repair. The prolonged cross-clamping time during open repair can result in compromised blood supply to the spinal cord, with subsequent paresis or paralysis.

Over the past 3 decades, various intraoperative strategies have been applied to protect the spinal cord and prevent such paraplegia with various levels of success, including left heart bypass, epidural cooling, ${ }^{1}$ motor evoked potential monitoring, ${ }^{2}$ and preoperative computed tomography (CT) angiography (CTA) and magnetic resonance angiography (MRA) to identify and preserve the artery of Adamkiewicz ${ }^{3}$ and provide cerebrospinal fluid (CSF) drainage. ${ }^{4,5}$

There is currently a class IB recommendation for CSF drainage for patients at high risk of SCI undergoing open DTAA or TAAA repair, according to the American College of Cardiology Foundation and American Heart Association guidelines, ${ }^{6}$ and a class IB recommendation for CSF drain (CSFD) use in all patients according to the European Association for Cardiothoracic Surgery guidelines. ${ }^{7}$ Here we present our experience with the use of CSFD as a protective strategy to prevent SCI in DTAA and TAAA open repair.

\section{METHODS}

Institutional Review Board approval for this study was obtained from the Human Investigation Committee at Yale University, and informed consent was considered unnecessary because of the study's retrospective nature.

Our database at the Aortic Institute at Yale-New Haven Hospital includes a total of 100 patients who underwent descending and thoracoabdominal aortic open repair with CSFD used as a protective strategy for the spinal cord between 2006 and 2017. During the study period, only 2 additional patients (operated on during the study period) did not undergo CSFD placement. The use of spinal drainage was so nearly uniform in our cohort that outcome comparisons with and without drain are not feasible. All patients who underwent endovascular repair procedures or did not undergo
CSFD placement were excluded. The Safi modification of Crawford's TAAA classification was used to describe the extent of aortic involvement. ${ }^{8}$

Postoperative clinical follow-up was assessed until hospital discharge to evaluate for lower extremity weakness or CSFD-related complications.

Family history was considered positive if the patient had a relative with TAAA or aortic dissection confirmed on an imaging study (CTA, MRA, transthoracic echocardiography, or transesophageal echocardiography), intraoperatively during surgery, or on autopsy. The electronic medical record (EPIC) was reviewed to record patient demographics, comorbidities, and symptoms at presentation.

\section{CSFD Technique (Video 1)}

Spinal drain insertion was performed mainly at 3 lumbar levels, most commonly L4-L5 but also L3-L4 and L2-L3. Two approaches were used for CSFD placement: with patient awake and sitting and postanesthesia induction with patient in the lateral decubitus position. We used a CSFD kit (model 46419; Medtronic Neurosurgery, Goleta, Calif; containing a Tuohy needle, 14 gauge, $9 \mathrm{~cm}$ [3-1/2"] with Huber tip, a 20-gauge blunt needle, and a guide wire), and a Duet External Drainage and Monitoring System with Baxter Interlink needleless injection sites, packaged with an 80-cm closed-tipped EDM lumbar drainage catheter (all Medtronic).

The Tuohy needle was inserted at the designated level using standard landmarks until clear CSF fluid was aspirated. Then the catheter was introduced an additional $\sim 6 \mathrm{~cm}$ past the needle. If paresthesias was encountered during needle introduction, needle advancement was stopped, and the needle was withdrawn approximately $5 \mathrm{~mm}$ until the patient confirmed complete resolution of paresthesia. Then the needle was redirected and advanced, and no paresthesia or pain confirmed. In 1 patient, a woman with a complex history of 4 previous lumbar spine operations, difficulty was encountered when placing the spinal drain. After several attempts, CSF was obtained via an L2 paramedian approach. The mean duration of CSFD placement was $2.3 \pm 0.72$ days. The goal was to maintain CSF pressure $<10 \mathrm{~mm} \mathrm{Hg}$ during the surgical procedure by draining CSF at a rate of 20 to $30 \mathrm{~mL} / \mathrm{h}$ when necessary. Postoperatively, CSFD is used to maintain the lumbar pressure at 5 to $12 \mathrm{~mm} \mathrm{Hg}$, to reduce the risk of postoperative SCI.

\section{Spinal Angiography}

CTA of the chest and abdomen were performed during infusion of iodinated contrast material and after administration of sublingual nitroglycerine (Figure 1). We scanned patients with a high-resolution or dual-energy technique based on patient size and also instrumental availability. A highspatial resolution time-resolved technique was used. Earlier in the series, occasional patients underwent magnetic resonance imaging or MRA
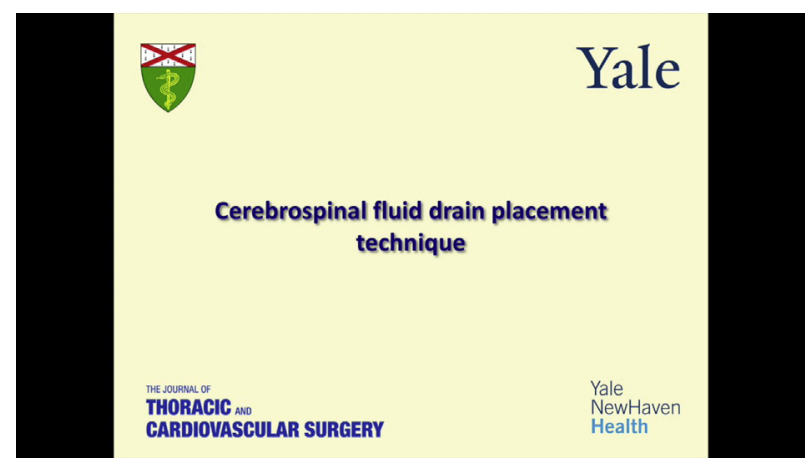

VIDEO 1. Placement of the cerebrospinal fluid drain before descending and thoracoabdominal aortic surgery. Video available at: https://www. jtcvs.org/article/S2666-2507(21)00025-0/fulltext. 


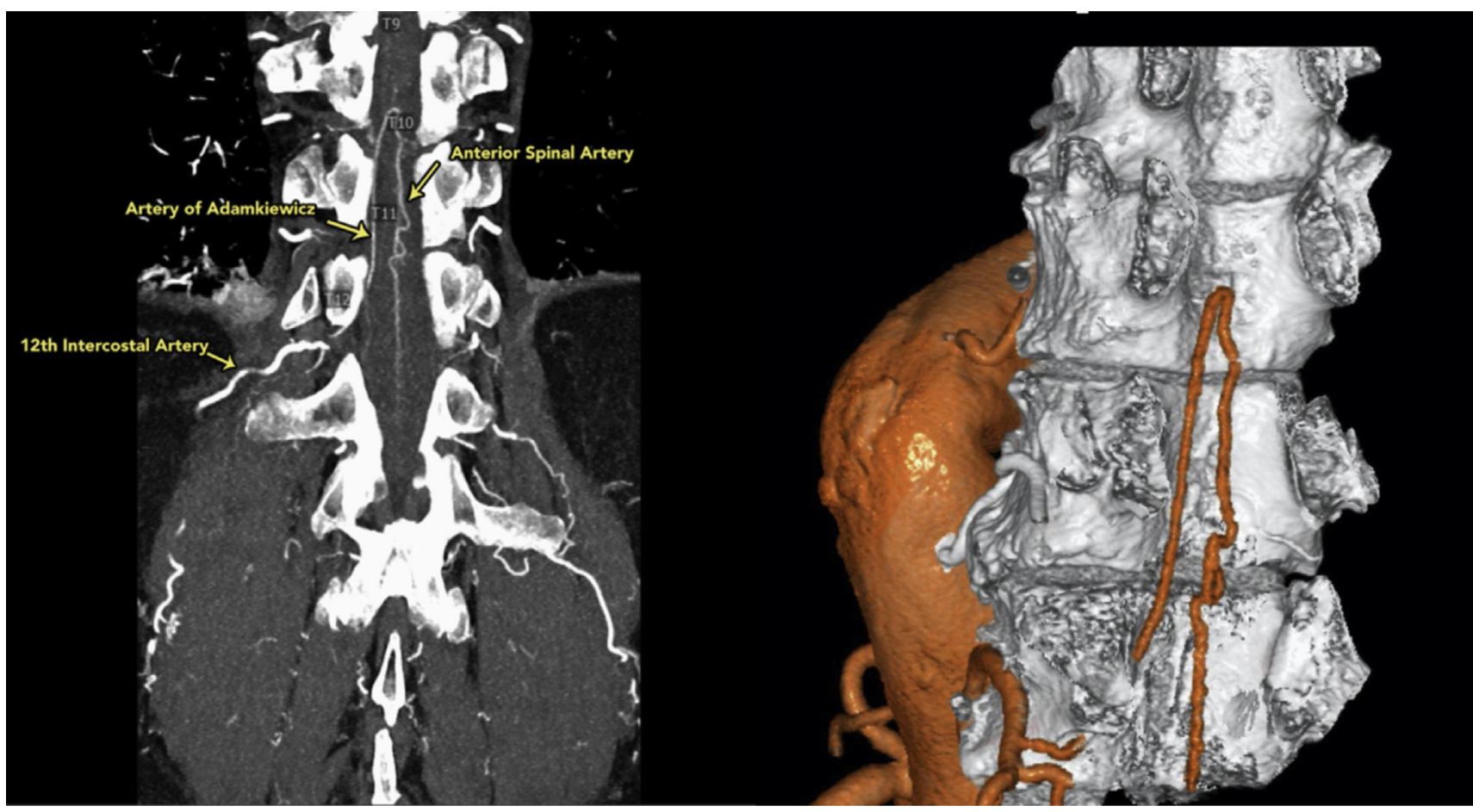

FIGURE 1. Visualization and 3-dimensional reconstruction of the anterior spinal artery (ASA) using a special dual-intensity Yale technique, which is part of our standard spinal cord protection regimen. The artery of Adamkiewicz is shown, arising from the 12th intercostal artery and joining the ASA.

instead of CTA. We did not evaluate the patency of reconstructed spinal arteries postoperatively. ${ }^{9}$

\section{Statistical Analysis}

Continuous variables are presented as mean \pm standard deviation, and categorical variables are presented as number and percentage. Survival was estimated using the Kaplan-Meier analytical method. $\mathrm{R}$ version 3.5.1 (R Foundation for Statistical Computing, Vienna, Austria), Windows Excel 2016 (Microsoft, Redmond, Wash), and Prism version 7.00 for Windows (GraphPad Software, La Jolla, Calif) were used for data analysis and visualization.

\section{RESULTS}

The mean patient age was $65.4 \pm 11.7$ years, and 60 of the 100 patients $(60 \%)$ were male. Patient characteristics are summarized in Table 1. Our cohort included 55 patients $(55 \%)$ with nondissected aneurysms, $43(43 \%)$ with dissected aneurysms, and $2(2 \%)$ who presented with contained aneurysm rupture. Only $2(2 \%)$ patients presented with an acute or subacute type B dissection. Thirty-three patients $(33 \%)$ had a DTAA and $67(67 \%)$ had a TAAA. Safi modification of the Crawford aneurysm classification was I in 26 patients ( $26 \%)$, II in $25(25 \%)$, III in $9(9 \%)$, IV in 3 $(3 \%)$, and $\mathrm{V}$ in $4(4 \%)$. The extent of surgical repair included the descending aorta in 48 patients $(48 \%)$, the thoracoabdominal aorta in 51 patients $(51 \%)$, and a combined aortic arch and descending aortic replacement in 1 patient. Thirty-six operations $(36 \%)$ were performed with a distal completion of a previously inserted elephant trunk, and only 8 operations $(8 \%)$ were performed urgently (Table 2 ).
Our policy is to use a spinal drain in all open descending and thoracoabdominal aortic cases regardless of extent. In rare cases, CSFD placement might not be feasible for anatomic reasons; in such cases, we proceed without the

TABLE 1. Patient characteristics and preoperative variables

\begin{tabular}{lc}
\hline \multicolumn{1}{c}{ Characteristic/variable } & Value \\
\hline Age, $\mathrm{y}$, mean $\pm \mathrm{SD}$ & $65.4 \pm 11.7$ \\
Male sex & $60(60)$ \\
\hline Height, $\mathrm{cm}$, mean $\pm \mathrm{SD}$ & $171.23 \pm 10.7$ \\
Weight, $\mathrm{kg}$, mean $\pm \mathrm{SD}$ & $79.08 \pm 17.9$ \\
\hline Body mass index, $\mathrm{kg} / \mathrm{m}^{2}$, mean $\pm \mathrm{SD}$ & $26.8 \pm 4.8$ \\
\hline Hypertension, $\mathrm{n}(\%)$ & $97(97)$ \\
\hline Diabetes, $\mathrm{n}(\%)$ & $15(15)$ \\
\hline Dyslipidemia, $\mathrm{n}(\%)$ & $54(54)$ \\
\hline Obesity, $\mathrm{n}(\%)$ & $25(25)$ \\
\hline Chronic obstructive pulmonary disease, $\mathrm{n}(\%)$ & $23(23)$ \\
\hline Chronic kidney disease, $\mathrm{n}(\%)$ & $16(16)$ \\
Coronary artery disease, $\mathrm{n}(\%)$ & $32(32)$ \\
\hline Marfan syndrome, $\mathrm{n}(\%)$ & $6(6)$ \\
\hline History of smoking, $\mathrm{n}(\%)$ & $66(66)$ \\
\hline Previous cardiac surgery (nonaortic), $\mathrm{n}(\%)$ & $27(27)$ \\
\hline Previous aortic surgery in proximal or distal & $66(66)$ \\
\hline segments, $\mathrm{n}(\%)$ & $16(16)$ \\
\hline Confirmed family history of aortic disease, $\mathrm{n}(\%)$ & \\
\hline$S D$, St &
\end{tabular}

$S D$, Standard deviation. 
TABLE 2. Primary diagnosis and related operative parameters

\begin{tabular}{lc}
\hline \multicolumn{1}{c}{ Parameter } & $\begin{array}{c}\text { Number of } \\
\text { patients }(\%)\end{array}$ \\
\hline Primary diagnosis & \\
$\quad$ Nondissected aneurysm & $55(55)$ \\
Dissected aneurysm: total, type A dissection, type & $43(43)$, \\
$\quad$ B dissection & $13(13), 30(30)$ \\
Contained rupture of aneurysm & $2(2)$ \\
Dissection & \\
Chronic type A & $13(13)$ \\
Acute/subacute type B & $2(2)$ \\
Chronic type B & $28(28)$ \\
\hline Location of primary diagnosis & \\
Descending aorta & $33(33)$ \\
Thoracoabdominal aorta & $67(67)$ \\
Crawford extent of TAAA & \\
Type I & $26(26)$ \\
Type II & $25(25)$ \\
Type III & $9(9)$ \\
Type IV & $3(3)$ \\
Type V & $4(4)$ \\
Extent of surgical repair & \\
Combined arch and descending aorta & $1(1)$ \\
Descending aorta & $48(48)$ \\
Thoracoabdominal aorta & $51(51)$ \\
Operations performed with distal completion of a & $36(36)$ \\
previously inserted elephant trunk (stage II & \\
elephant trunk) via left thoracotomy & \\
\hline Operation & \\
Elective & \\
Urgent & \\
\hline TAAA, Thon & \\
\hline
\end{tabular}

TAAA, Thoracoabdominal aortic aneurysm.

drain. In this era, open surgery for acute aortic dissection is rare. In the event of frank rupture of the aorta with hemodynamic instability, we would proceed without a drain.

Various intraoperative protective strategies besides CSFD were applied to reduce the incidence of SCI. Our standard spinal cord protection regimen includes preoperative identification of the origin of the spinal artery by dual-energy CT scan $^{9}$ with intraoperative preservation of intercostal arteries, routine use of spinal drain, left atrialfemoral artery bypass (with an oxygenator) ${ }^{10}$ intraoperative motor evoked potential monitoring, and maintenance of systolic blood pressure $>125 \mathrm{~mm} \mathrm{Hg}$ from 2 hours postoperatively onward. These intraoperative strategies were adopted in each patient on individual basis according to the surgeon's discretion (Table 3). We cannot differentiate the impact of these different protective modalities, as all were used essentially throughout the period of this clinical experience. We routinely use a pulmonary artery (SwanGanz) catheter. Regarding fluid management, we match urine output and chest tube drainage at a minimum. We believe that a hematocrit concentration of $\geq 30 \%$ is
TABLE 3. Intraoperative protection strategies

\begin{tabular}{lc}
\hline \multicolumn{1}{c}{ Protection strategy } & Number (\%) \\
\hline Preserving intercostals & $72(72)$ \\
Motor evoked potentials & $67(67)$ \\
\hline Anterior spinal artery detected before surgery & $67(67)$ \\
Left atrial-femoral bypass & $96(96)$ \\
\hline
\end{tabular}

necessary to maintain adequate oxygen delivery to the spinal cord, as well as to maintain adequate coagulation and achieve surgical hemostasis. We do not use any pharmacologic adjuncts (eg, glucocorticoids) in the perioperative period. Our strategy does not differ significantly from the UT Memorial Herrmann group's "COPS" perioperative strategy. ${ }^{11}$ The main difference is preoperative visualization of the anterior spinal artery, which is routinely used at our institution.

The Yale Aortic Institute survival assessment technique ${ }^{12}$ and Kaplan-Meier analytical method were used to assess survival rates (Figure 2). The 1-year, 3-year, 5-year, and 10 -year survival rates for the overall cohort were $86.9 \%$ (95\% confidence interval [CI], 80.6\%-93.8\%), 83.8\% (95\% CI, 76.9\%-91.4\%), 77.5\% (95\% CI, 69.1\%-87\%) and $68.4(95 \%$ CI $55.5 \%-84.3 \%)$ respectively.

Six patients $(6 \%)$ experienced in-hospital postoperative mortality. One patient $(1 \%)$ died intraoperatively due to diffuse coagulopathic hemorrhage, and $2(2 \%)$ patients died within 30 days of the operation but after hospital discharge. Mortality and major postoperative complications by type of aneurysm and Crawford extent are presented in Table 4 . The majority of complications occurred in the patients with extensive aneurysms (Crawford type I and II).

In our study cohort, 6 patients sustained SCI, $4(4 \%)$ of them with transient lower extremity weakness and the other $2(2 \%)$ with permanent paraplegia, 1 of whom died in the hospital as a result of multisystem organ failure. The other patient, who had a contained rupture of a large type I TAAA, developed lower extremity weakness on postoperative day 5 after TAAA repair, which subsequently progressed to complete paraplegia. A CSFD had been removed previously, with no leak on the second postoperative day. The CSFD was reinserted as soon as the weakness was noted, revealing normal spinal fluid pressure. CT of the head revealed no acute intracranial hemorrhage, territorial infarct, or hydrocephalus.

Furthermore, 5 patients (5\%) sustained a stroke, $9(9 \%)$ had respiratory failure with tracheostomy, and $2(2 \%)$ had renal failure necessitating dialysis. The majority of these complications occurred in patients with Crawford type I or type II aneurysms (the most extensive type). The mean hospital length of stay after surgery was $11.9 \pm 11.8$ days.

CSFD-related complications were reported in 14 patients (14\%) (Table 5). Persistent CSF leakage was reported in 7 


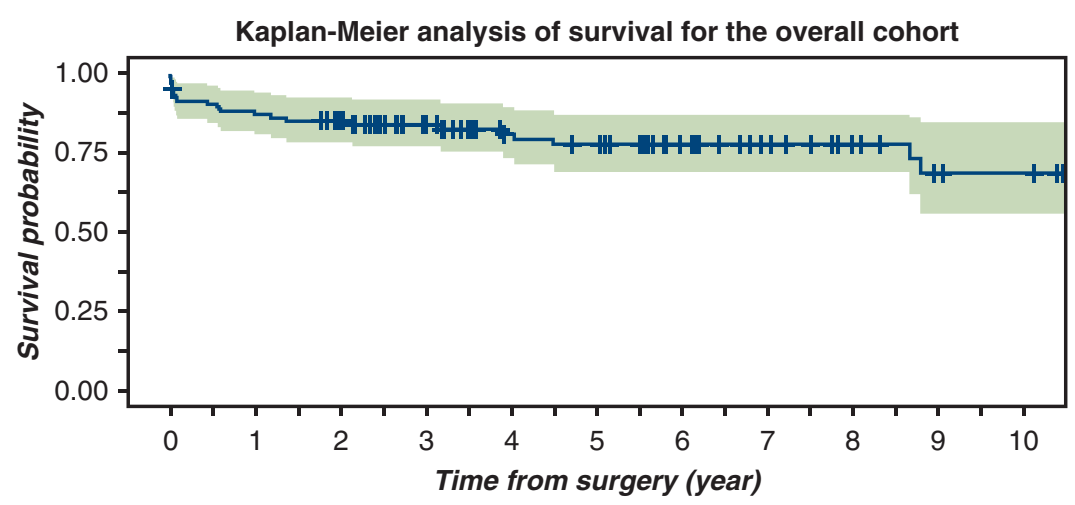

Number at risk

\begin{tabular}{ccccccccccc}
-100 & 86 & 80 & 62 & 49 & 46 & 33 & 25 & 19 & 14 & 13 \\
\hline 0 & 1 & 2 & 3 & 4 & 5 & 6 & 7 & 8 & 9 & 10 \\
Time from surgery (year) & & & &
\end{tabular}

FIGURE 2. Kaplan-Meier analysis of survival for 100 patients who underwent cerebrospinal fluid drain (CSFD) placement before open descending or thoracoabdominal aortic repair between 2006 and 2017. The 1-year, 3-year, 5-year, and 10-year survival rates for the overall cohort were 86.9\% (95\% confidence interval [CI], 80.6\%-93.8\%), 83.8\% (95\% CI, 76.9\%-91.4\%), 77.5\% (95\% CI, 69.1\%-87\%), and 68.4 (95\% CI, 55.5\%-84.3\%), respectively.

patients $(7 \%)$. Five of these patients experienced headache at the time of leakage, which was managed with acetaminophen. In cases where acetaminophen did not relieve the spinal headache, we occasionally used caffeine, tramadol, or ketorolac. We moved to a blood patch when the spinal headache persisted for 48 to 72 hours. The leakage was controlled by suturing the insertion site in 3 patients and by applying extra dressing to the site in 4 patients. One patient $(1 \%)$ with persistent CSF leakage and headache was found to have a spinal cutaneous fistula on postoperative day 7. A single stitch was used to seal the fistula, without any further complications. Blood-tinged CSF was noted in 9 patients $(9 \%) ; 7$ of these patients did not develop any neurologic symptoms, and their CSF became clear after monitoring. In the rare case of a frankly bloody tap, we would delay an elective procedure to avoid causing hemorrhage into the spinal canal upon heparinization. Three patients $(3 \%)$ with blood-tinged CSF underwent a CT scan of the head. Findings were normal in 2 patients, but 1 patient had concomitant leakage with headache, and brain $\mathrm{CT}$ revealed no abnormalities.

Another patient exhibited failure to wake up in presence of bloody CSF on the second postoperative day. The CSFD was removed on the third postoperative day. Brain CT performed on postoperative day 13 showed a subdural hemorrhage. The blood in the CSF and the intracranial hemorrhage were both attributed to active coagulopathy postoperatively. The patient died on postoperative day 15 .

TABLE 4. Mortality and major postoperative complications analyzed by aneurysm extent

\begin{tabular}{|c|c|c|c|c|c|c|c|}
\hline Parameter & $\begin{array}{c}\text { DTAA } \\
(\mathbf{N}=\mathbf{3 3})\end{array}$ & $\begin{array}{c}\text { Type I TAAA } \\
\quad(\mathbf{N}=\mathbf{2 6})\end{array}$ & $\begin{array}{c}\text { Type II TAAA } \\
\quad(\mathbf{N}=\mathbf{2 5})\end{array}$ & $\begin{array}{l}\text { Type III TAAA } \\
\qquad(\mathbf{N}=9)\end{array}$ & $\begin{array}{c}\text { Type IV TAA } \\
\quad(\mathbf{N}=\mathbf{3})\end{array}$ & $\begin{array}{c}\text { Type V TAAA } \\
\quad(N=4)\end{array}$ & $\begin{array}{l}\text { All patients } \\
(\mathbf{N}=100)\end{array}$ \\
\hline $\begin{array}{l}\text { In-hospital mortality } \\
\quad \text { (postoperative), } \mathrm{n}(\%)\end{array}$ & & $2(8)$ & $3(12)$ & & & $1(25)$ & $6(6)$ \\
\hline $\begin{array}{l}\text { 30-d mortality (after hospital } \\
\text { discharge), } \mathrm{n}(\%)\end{array}$ & $1(3)$ & $1(4)$ & & & & & $2(2)$ \\
\hline Paraplegia, n (\%) & & $1(4)$ & $1(12)$ & & & & $2(2)$ \\
\hline $\begin{array}{r}\text { Transient extremity } \\
\text { weakness, } \mathrm{n}(\%)\end{array}$ & $1(3)$ & $1(4)$ & & $1(11)$ & & $1(25)$ & $4(4)$ \\
\hline Stroke, n (\%) & $1(3)$ & $1(4)$ & $2(24)$ & & & $1(25)$ & $5(5)$ \\
\hline $\begin{array}{l}\text { Respiratory failure with } \\
\text { tracheostomy, n }(\%)\end{array}$ & $4(12)$ & $3(12)$ & $1(11)$ & $1(11)$ & & & $9(9)$ \\
\hline $\begin{array}{l}\text { Renal failure requiring } \\
\text { dialysis, } \mathrm{n}(\%)\end{array}$ & & $1(4)$ & $1(11)$ & & & & $2(2)$ \\
\hline
\end{tabular}


TABLE 5. CSFD complications (may be multiple for each individual patient)

\begin{tabular}{lc}
\hline \multicolumn{1}{c}{ CSFD complication } & Number $(\%)$ \\
\hline Persistent CSF leakage & $7(7)$ \\
Blood-tinged CSF & $9(9)$ \\
Spinal cutaneous fistula & $1(1)$ \\
Subdural hematoma & $1(1)$ \\
\hline
\end{tabular}

$C S F D$, Cerebrospinal fluid drain; $C S F$, cerebrospinal fluid.

No patient required reintervention as a result of CSFD complications. We always remove the spinal drain on the morning of the second postoperative day. The only exception is made in cases with neurologic impairment or concern.

\section{DISCUSSION}

\section{Complications of CSFD}

CSFD has its own complications, which can vary in severity, and can be related to placement or removal of the drain, drainage itself, and risks related to the indwelling catheter. The complication spectrum can vary from bloody spinal fluid without any evidence of intracranial hemorrhage on CT scan to intracranial bleeding without neurologic deficits to intracranial bleeding with cerebral injury and neurologic deficits. ${ }^{13}$

Another rare but fatal complication of CSFD is brain herniation as a result of intracranial hypotension due to excessive CSF drainage leading to brain sag and brain stem herniation. ${ }^{14}$ We did not encounter this complication in any of our patients.

Another recognized complication of CSFD is meningeal tear with persistent CSF leakage, which can result in pseudomeningocele, cutaneous fistula, meningitis, and even epidural abscess. ${ }^{15,16}$ One patient in our study suffered a spinal cutaneous fistula, with clear CSF leak noted on postoperative day 7.

A meta-analysis by Rong and colleagues ${ }^{17}$ showed pooled rates of severe, moderate, and mild CSFD complications of $2.5 \%, 3.7 \%$, and $2 \%$, respectively. A recent large meta-analysis by Gaudino and colleagues ${ }^{18}$ demonstrated similar complication rates of $5.0 \%, 4.0 \%$ and $4.0 \%$, respectively. In the present analysis, $14 \%$ of patients experienced CSFD complications, the majority of which were mild.

In our study cohort, 6 patients (6\%) sustained SCI, with permanent paraplegia in 2 patients $(2 \%)$ and transient lower extremity weakness in $4(4 \%)$. These results are in line with a large observational study reported by Coselli and colleagues ${ }^{19}$ in which $5.4 \%$ of 3309 patients suffered permanent paraplegia or paraparesis, as well as a recent meta-analysis that reported a pooled rate of permanent SCI of $5.7 \%$ in open aortic repairs $(P=.03) .{ }^{18}$

\section{Efficacy of CSFD}

Perioperative application of CSFD has shown efficacy in protecting the spinal cord and decreasing paraplegia rates in both open and endovascular TAAA repair. ${ }^{4,20}$

\section{Safety of Perioperative Cerebrospinal Fluid Drainage as a Protective Strategy During Descending and Thoracoabdominal Open Aortic Replacement}

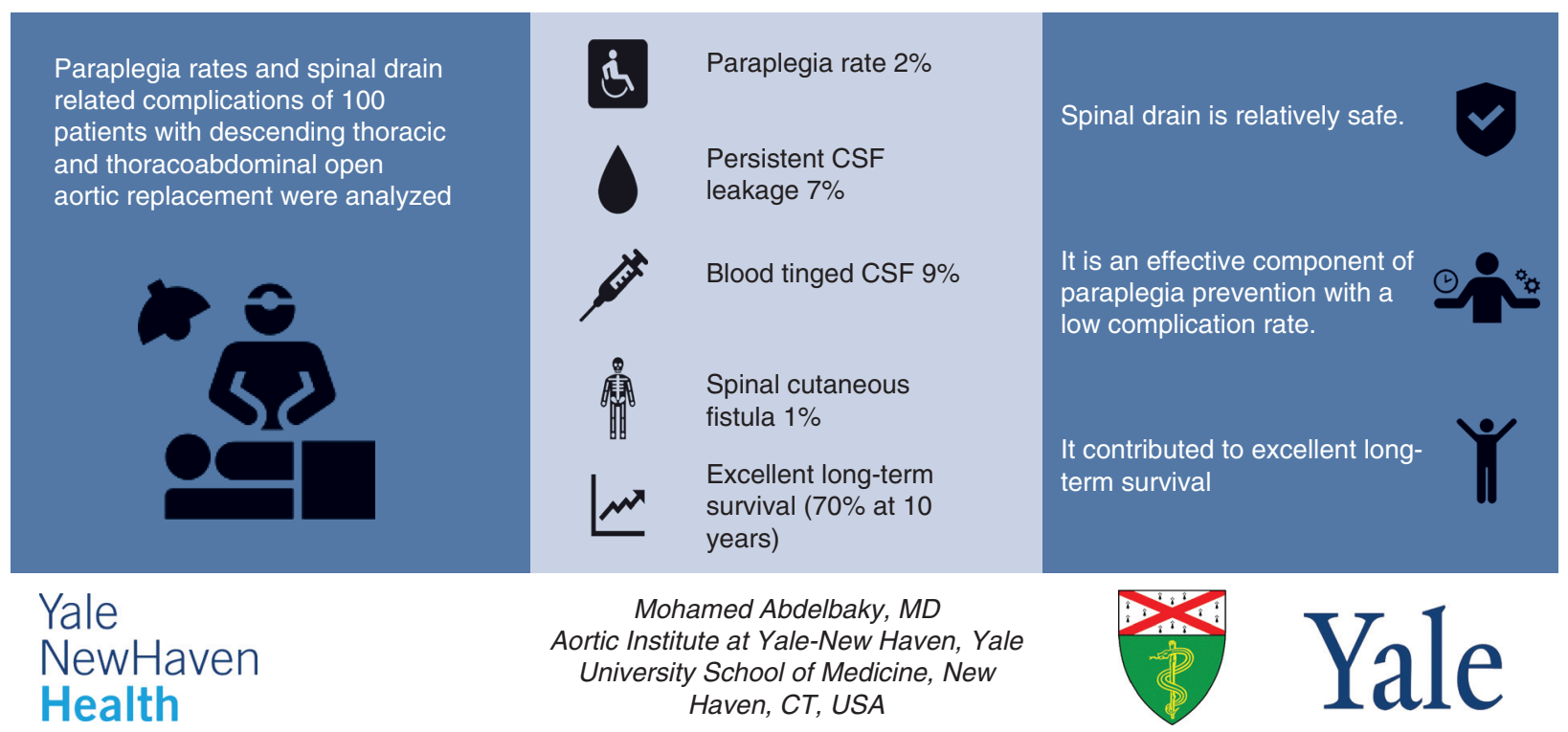

FIGURE 3. Summarizing the findings of this study, we conclude that (1) spinal drain placement before open descending or thoracoabdominal aortic repair is relatively safe; (2) it is an effective component of paraplegia prevention with a low complication rate; and (3) it contributed to excellent long-term survival $(70 \%)$ in our cohort. $C S F$, Cerebrospinal fluid. 
The use of CSFD has also received a class I recommendation by the American College of Cardiology Foundation/American Heart Association guidelines on the management of thoracic aortic diseases as a protective strategy for endovascular and open thoracic aortic repair. ${ }^{6}$

The concept of the CSFD stems from the understanding that spinal cord perfusion pressure is the difference between blood pressure and CSF pressure. ${ }^{21}$ Over the past few decades, the relationship between CSF pressure and SCI and the bona fide role of CSF drainage in paraplegia have been well established. ${ }^{22-24}$ The aortic cross-clamping during descending aortic repair is accompanied by an acute increase in the CSF pressure whether or not a distal femoral bypass is applied. ${ }^{25}$ A possible explanation for this phenomenon is that the aortic cross-clamping induces vasoconstriction in the systematic and spinal cord thin-walled veins through the sympathetic nervous system, which may lead to decreases in the critical closing pressure required to induce collapse in the radiculospinal veins, with subsequent venous engorgement and increase in the CSF pressure. ${ }^{25} \mathrm{An}$ animal study showed an improvement in spinal cord blood flow after CSF drainage during aortic cross-clamping in the lower thoracic aorta. ${ }^{26} \mathrm{~A}$ randomized controlled study by Coselli and colleagues ${ }^{20}$ including 145 patients undergoing graft repair for type I and type II TAA with the use of CSFD found paraplegia in 9 patients in the control group $(n=69)$ versus 2 patients in the CSFD group $(\mathrm{n}=76)(P=.03)$.

A retrospective cohort study reviewed 1004 patients who underwent thoracic or thoracoabdominal open repairs over a 12-year period, including 741 patients $(74 \%)$ who had distal aortic perfusion with CSFD and 263 patients who were treated previously by the traditional clamp-and-go technique. ${ }^{8}$ The incidence of SCI was $2.4 \%$ in the CSFD adjunct group compared with $6.8 \%$ in the nonadjunct group $(P<.0009)$. Furthermore, the study showed a more evident benefit in patients at high risk for SCI (ie, patients with aneurysm distal to the left subclavian artery to below the renal arteries), with SCI occurring in 11 of $167(6.6 \%)$ in the adjunct group versus 11 of $38(29 \%)$ in the nonadjunct group. ${ }^{8}$ In the present study, the paraplegia rate was low, and CSFD may have contributed to these favorable results.

\section{Limitations}

This is an observational study aimed specifically at determining the frequency and severity of complications related to the spinal drain in our experience with open descending and thoracoabdominal aortic operations. The study did not compare "drain" and "no drain" groups or offer evidence to support or discourage the use of CSFD for paraplegia prevention.

\section{CONCLUSIONS}

A CSFD can be applied safely as a component of protective strategy and with favorable neurologic outcomes for
DTAA and TAAA repair with low complication rates (Figure 3).

\section{Conflict of Interest Statement}

Dr Elefteriades is a Principal of CoolSpine, a member of the Data and Safety Monitorin Board of Terumo, and a Consultant for CryoLife. All other authors reported no conflicts of interest.

The Journal policy requires editors and reviewers to disclose conflicts of interest and to decline handling or reviewing manuscripts for which they may have a conflict of interest. The editors and reviewers of this article have no conflicts of interest.

We thank Drs Hamid Mojibian and Steffen Huber from Yale Radiology and Biomedical imaging for providing us with the CT scan and 3-dimensional construction of the anterior spinal artery for the central picture.

\section{References}

1. Cambria RP, Davison JK, Carter C, Brewster DC, Chang Y, Clark KA, et al. Epidural cooling for spinal cord protection during thoracoabdominal aneurysm repair: a five-year experience. J Vasc Surg. 2000;31:1093-102.

2. Liu LY, Callahan B, Peterss S, Dumfarth J, Tranquilli M, Ziganshin BA, et al. Neuromonitoring using motor and somatosensory evoked potentials in aortic surgery. J Card Surg. 2016;31:383-9.

3. Amako M, Yamamoto Y, Nakamura K, Tobinaga S, Nakamura E, Hosokawa Y, et al. Preoperative visualization of the artery of Adamkiewicz by dual-phase CT angiography in patients with aortic aneurysm. Kurume Med J. 2011;58:117-25.

4. Epstein NE. Cerebrospinal fluid drains reduce risk of spinal cord injury for thoracic/thoracoabdominal aneurysm surgery: a review. Surg Neurol Int. 2018; $9: 48$.

5. Ziganshin BA, Elefteriades JA. Surgical management of thoracoabdominal aneurysms. Heart. 2014;100:1577-82.

6. Hiratzka LF, Bakris GL, Beckman JA, Bersin RM, Carr VF, Casey DE Jr, et al. 2010 ACCF/AHA/AATS/ACR/ASA/SCA/SCAI/SIR/STS/SVM guidelines for the diagnosis and management of patients with thoracic aortic disease. A report of the American College of Cardiology Foundation/American Heart Association task force on practice guidelines, American Association for Thoracic Surgery, American College of Radiology, American Stroke Association, Society of Cardiovascular Anesthesiologists, Society for Cardiovascular Angiography and Interventions, Society of Interventional Radiology, Society of Thoracic Surgeons, and Society for Vascular Medicine. J Am Coll Cardiol. 2010;55: e27-129.

7. Etz CD, Weigang E, Hartert M, Lonn L, Mestres CA, Di Bartolomeo R, et al. Contemporary spinal cord protection during thoracic and thoracoabdominal aortic surgery and endovascular aortic repair: a position paper of the vascular domain of the European Association for Cardio-Thoracic Surgery. Eur J Cardiothorac Surg. 2015;47:943-57.

8. Safi HJ, Miller CC III, Huynh TT, Estrera AL, Porat EE, Winnerkvist AN, et al. Distal aortic perfusion and cerebrospinal fluid drainage for thoracoabdominal and descending thoracic aortic repair: ten years of organ protection. Ann Surg. 2003;238:372-80; discussion 380-1.

9. Abdelbaky M, Zafar MA, Saeyeldin A, Wu J, Papanikolaou D, Vinholo TF, et al. Routine anterior spinal artery visualization prior to descending and thoracoabdominal aneurysm repair: high detection success. J Card Surg. 2019;34: 1563-8.

10. Papanikolaou D, Savio C, Zafar MA, Freudzon L, Wu J, Abdelbaky M, et al. Lef atrial to femoral artery full cardiopulmonary bypass: a novel technique for descending and thoracoabdominal aortic surgery. Int J Angiol. 2020;29:19-26.

11. Estrera AL, Sheinbaum R, Miller CC III, Harrison R, Safi HJ. Neuromonitorguided repair of thoracoabdominal aortic aneurysms. J Thorac Cardiovasc Surg. 2010;140(6 Suppl):S131-5; discussion S142-6. 
12. Peterss S, Charilaou P, Ziganshin BA, Elefteriades JA. Assessment of survival in retrospective studies: the social security death index is not adequate for estimation. J Thorac Cardiovasc Surg. 2017;153:899-901.

13. Wynn MM, Mell MW, Tefera G, Hoch JR, Acher CW. Complications of spinal fluid drainage in thoracoabdominal aortic aneurysm repair: a report of 486 patients treated from 1987 to 2008. J Vasc Surg. 2009;49:29-34; discussion 34-5.

14. Kim YS, Kim SH, Jung SH, Kim TS, Joo SP. Brain stem herniation secondary to cerebrospinal fluid drainage in ruptured aneurysm surgery: a case report. Springerplus. 2016;5:247.

15. Tosun B, Ilbay K, Kim MS, Selek O. Management of persistent cerebrospinal fluid leakage following thoraco-lumbar surgery. Asian Spine J. 2012;6: 157-62.

16. Koo J, Adamson R, Wagner FC Jr, Hrdy DB. A new cause of chronic meningitis: infected lumbar pseudomeningocele. Am J Med. 1989;86:103-4.

17. Rong LQ, Kamel MK, Rahouma M, White RS, Lichtman AD, Pryor KO, et al. Cerebrospinal-fluid drain-related complications in patients undergoing open and endovascular repairs of thoracic and thoraco-abdominal aortic pathologies: a systematic review and meta-analysis. Br J Anaesth. 2018;120: 904-13.

18. Gaudino M, Khan FM, Rahouma M, Naik A, Hameed I, Spadaccio C, et al. Spinal cord injury after open and endovascular repair of descending thoracic and thoracoabdominal aortic aneurysms: a meta-analysis. J Thorac Cardiovasc Surg. May 13, 2020 [Epub ahead of print].

19. Coselli JS, LeMaire SA, Preventza O, de la Cruz KI, Cooley DA, Price MD, et al. Outcomes of 3309 thoracoabdominal aortic aneurysm repairs. J Thorac Cardiovasc Surg. 2016;151:1323-37.
20. Coselli JS, LeMaire SA, Köksoy C, Schmittling ZC, Curling PE. Cerebrospinal fluid drainage reduces paraplegia after thoracoabdominal aortic aneurysm repair: results of a randomized clinical trial. J Vasc Surg. 2002;35:631-9.

21. Estrera AL, Sheinbaum R, Miller CC, Azizzadeh A, Walkes JC, Lee TY, et al. Cerebrospinal fluid drainage during thoracic aortic repair: safety and current management. Ann Thorac Surg. 2009;88:9-15; discussion 15.

22. McCullough JL, Hollier LH, Nugent M. Paraplegia after thoracic aortic occlusion: influence of cerebrospinal fluid drainage. Experimental and early clinical results. J Vasc Surg. 1988;7:153-60.

23. Miyamoto K, Ueno A, Wada T, Kimoto S. A new and simple method of preventing spinal cord damage following temporary occlusion of the thoracic aorta by draining the cerebrospinal fluid. J Cardiovasc Surg (Torino). 1960;1:188-97.

24. Blaisdell FW, Cooley DA. The mechanism of paraplegia after temporary thoracic aortic occlusion and its relationship to spinal fluid pressure. Surgery. 1962;51: $351-5$.

25. Drenger B, Parker SD, Frank SM, Beattie C. Changes in cerebrospinal fluid pressure and lactate concentrations during thoracoabdominal aortic aneurysm surgery. Anesthesiology. 1997;86:41-7.

26. Bower TC, Murray MJ, Gloviczki P, Yaksh TL, Hollier LH, Pairolero PC. Effects of thoracic aortic occlusion and cerebrospinal fluid drainage on regional spinal cord blood flow in dogs: correlation with neurologic outcome. J Vasc Surg. 1989;9:135-44.

Key Words: spinal protection, descending aneurysm, thoracoabdominal aneurysm 